\title{
Altered Calcium Metabolism in Aging CA1 Hippocampal Pyramidal Neurons
}

\author{
M. Matthew $0 h,{ }^{\star}$ Fernando A. Oliveira, ${ }^{*}$ Jack Waters, $\dagger$ and John F. Disterhoft $\dagger$ \\ Department of Physiology, Feinberg School of Medicine, Northwestern University, Chicago, Illinois 60611
}

\begin{abstract}
Altered neuronal calcium homeostasis is widely hypothesized to underlie cognitive deficits in normal aging subjects, but the mechanisms that underlie this change are unknown, possibly due to a paucity of direct measurements from aging neurons. Using CCD and two-photon calcium imaging techniques on CA1 pyramidal neurons from young and aged rats, we show that calcium influx across the plasma membrane increases with aging, and that this change is countered by increased intracellular calcium buffering. The additional buffer in aging neurons balances the increased calcium influx following a small number $(<3)$ action potentials, but is overwhelmed during sustained or theta-like activity which leads to a greater rise in intracellular calcium concentration in aging than that in young neurons. Our results demonstrate that calcium overload occurs regularly in aging CA1 pyramidal neurons under physiological conditions. This overload may be a critical factor in age-related decline in hippocampus-dependent cognitive function.
\end{abstract}

\section{Introduction}

The calcium hypothesis of brain aging (for review, see Gibson and Peterson, 1987; Landfield, 1987; Khachaturian, 1989; Disterhoft et al., 1994) has been a theoretical touch-point for neuroscientists studying aging-related alterations of brain function and cognitive deficits. A tenet of the hypothesis is that homeostatic cellular mechanisms that regulate cytosolic free calcium in neurons are changed during the normal aging process and that these changes contribute to aging-related cognitive deficits. However, evidence for the hypothesis, thus far, has been mixed. Numerous studies have reported increased levels of resting free $\mathrm{Ca}^{2+}$ ions in aging subjects (Michaelis et al., 1992; Kirischuk and Verkhratsky, 1996; Tonkikh et al., 2006; Hajieva et al., 2009), although there are also reports of no change (Murchison and Griffith, 1998; Thibault et al., 2001; Gant et al., 2006) or reduced (Gibson and Peterson, 1987) levels of free $\mathrm{Ca}^{2+}$ with aging. There have also been reports of changes in endogenous calcium buffer capacity during aging. For example, endogenous buffer capacity is enhanced in dissociated basal forebrain neurons of aged rats (Murchison and Griffith, 1998). However, many reports conclude that endogenous buffer capacity is reduced in

Received Nov. 21, 2012; revised March 19, 2013; accepted March 27, 2013.

Author contributions: M.M.O., F.A.O., J.W., and J.D. designed research; M.M.O. and F.A.0. performed research; M.M.O., F.A.O., J.W., and J.D. analyzed data; M.M.O., F.A.O., J.W., and J.D. wrote the paper.

This work was supported by NIH Grants AG08796 and AG017139 (J.F.D.) and AG20506 (J.W.).2P-LSM experiments were performed in the MP-Core2 facility (NINDS P30NS054850). We thank Dr. David Wokosin for technical assistance, Dr. Miguel Maravall for advice on analysis, and Drs. Gordon Shepherd, Murali Prakriya, and Robert Vassar for discussions.

${ }^{*}$ M.M.O. and F.A.O. contributed equally as first authors.

†J.W. and J.F.D. contributed equally as second authors.

The authors declare no competing financial interests.

Correspondence should be addressed to either Dr. John F. Disterhoft or Dr. Jack Waters, Department of Physiology, Feinberg School of Medicine, Northwestern University, 303 E Chicago Avenue, Chicago, IL 60611, E-mail: jackwaters@northwestern.edu or jdisterhoft@northwestern.edu.

F.A. Oliveira's present address: Departamento de Ciências Biológicas, Setor de Fisiologia e Farmacologia, Universidade Federal de São Paulo (UNIFESP), São Paulo, SP, Brazil.

DOI:10.1523/JNEUROSCI.5457-12.2013

Copyright $\odot 2013$ the authors $\quad 0270-6474 / 13 / 337905-07 \$ 15.00 / 0$ intact neurons from aging animals, especially in the hippocampus (Tonkikh et al., 2006; Kumar et al., 2009). Hence, there are conflicting reports regarding which elements of calcium homeostasis change with aging and the direction of these changes. In some cases the contradictory conclusions may result from different methodologies (e.g., from different rodent species or strain, cell type, indicator, method of loading indicator, and calibration), but in many studies these conclusions were drawn from indirect measurements and there is a general paucity of direct measurements of calcium metabolism from aging neurons.

Here we provide evidence of aging-related alteration in calcium homeostasis by directly examining calcium metabolism (calcium influx, resting calcium concentration, and endogenous buffer capacity) in the proximal apical dendrite of CA1 pyramidal neurons in acute slices prepared from young adult (2-4-monthold) and aging (29-31-month-old) rats, using fluorescencebased calcium imaging techniques. Our results indicate that action potential-evoked calcium influx and the endogenous buffer capacity of CA1 pyramidal neurons are both increased during aging, suggesting that pharmacological manipulations that further increase calcium buffer capacity in aging neurons may rescue the cognitive deficits observed in normal aging subjects.

\section{Materials and Methods}

Subjects. Young adult (2-4-month-old) and aged (29-31-month-old) male Fischer $344 \times$ Brown Norway rats were used in this study. We followed procedures that were approved by the Northwestern University's Animal Care and Use Committee and that were in accordance with the guidelines established by the National Institutes of Health Guide for the Care and Use of Laboratory Animals and the Society for Neuroscience.

Hippocampal slice preparation. Three-hundred-micrometer-thick transverse hippocampal slices were prepared using a Leica VT1000 s vibratome as described previously (Moyer and Brown, 1998; McKay et al., 2009). Briefly, rats were deeply anesthetized with isoflurane and decapitated. The brains were quickly removed, immersed in ice-cold cutting solution bubbled with $95 \% \mathrm{O}_{2} / 5 \% \mathrm{CO}_{2}$ and sliced. For young-adult rats, the cutting solution was the artificial CSF (aCSF) used throughout 
the experiments and was composed of the following (in $\mathrm{mm}$ ): $125 \mathrm{NaCl}$, $2.5 \mathrm{KCl}, 1.25 \mathrm{NaH}_{2} \mathrm{PO}_{4}, 26 \mathrm{NaHCO}_{3}, 2 \mathrm{CaCl}_{2}, 1 \mathrm{MgSO}_{4}$, and 25 glucose. For the aged rats, the cutting solution was a sucrose-aCSF that contained the following (in mM): 206 sucrose, $2.5 \mathrm{KCl}, 1.25 \mathrm{NaH}_{2} \mathrm{PO}_{4}, 26 \mathrm{NaHCO}_{3}$, $0.1 \mathrm{CaCl}_{2}, 3 \mathrm{MgSO}_{4}$, and 25 glucose. The cut slices were transferred immediately to a warm $\left(37^{\circ} \mathrm{C}\right)$ submerged holding chamber filled with aCSF and kept in this chamber for $30 \mathrm{~min}$. Afterward, the slices in the warmed submerged holding chamber were allowed to gradually return to room temperature $\left(22-25^{\circ} \mathrm{C}\right)$ for at least another 30 min before use.

Electrophysiology. Slices were placed in a submerged recording chamber and were perfused with oxygenated aCSF warmed to $32-34^{\circ} \mathrm{C}$ using an in-line heater and temperature controller (Warner Instruments). Whole-cell recordings were made from visualized CA1 pyramidal neurons using either a CCD camera (C4742-95, Hamamatsu) mounted on a Leica DM LFS or a near IR camera (IR1000, Dage MTI) mounted on an Olympus BX51 microscope; both microscopes were equipped with long working distance $40 \times(0.8 \mathrm{NA})$ water-immersion objectives and infrared differential interference contrast optics. Patch pipettes were 4-6 M $\Omega$ when filled with an internal solution containing the following (in $\mathrm{mM}$ ): $120 \mathrm{~K}_{-} \mathrm{MeSO}_{4}, 10 \mathrm{KCl}, 10 \mathrm{HEPES}, 10 \mathrm{Na}_{2}$-phosphocreatine, $4 \mathrm{Mg}_{2}$-ATP, $0.4 \mathrm{Na}_{3}-\mathrm{GTP}, 20 \mu \mathrm{M}$ Alexa 594, and a calcium indicator.

A cell was omitted from further analysis if the holding current necessary to hold the membrane potential at $-70 \mathrm{mV}$ exceeded $\pm 200 \mathrm{pA}$. Resting membrane potential was measured immediately after breaking into the cell. Input resistance was calculated as the slope of the voltagecurrent curve using $500 \mathrm{~ms}$ current steps from $-300 \mathrm{pA}$ to $200 \mathrm{pA}$ at 50 pA steps. Action potentials (APs) were evoked using brief current pulses $(2 \mathrm{~ms}, 2.5 \mathrm{nA})$. AP threshold was measured where the first derivative of the up phase of the trace was equal $40 \mathrm{mV} / \mathrm{ms}$. AP amplitude was calculated as the difference from the maximum depolarization and the AP threshold. Electrophysiological data were acquired with a Multiclamp $700 \mathrm{~B}$ or an Axoclamp 2A amplifier (Molecular Devices) and digitized at $10 \mathrm{kHz}$ (filtered at $2-3 \mathrm{kHz}$ ) using Winfluor software (Dr. John Dempster, University of Strathclyde, UK) or routines in Labview 8.5 (National Instruments).

CCD imaging. Oregon green BAPTA-1 [(OGB-1) Invitrogen] was added to the intracellular recording solution. Fluorescence was collected using a $40 \times / 0.8 \mathrm{NA}$ water-immersion objective (Leica Microsystems) and a CCD camera at $43 \mathrm{~Hz}$. The slice was illuminated during data collection with a blue LED (Thorlabs), and the emitted green light was detected through a $505 \mathrm{~nm}$ long-pass dichroic mirror and a 512-542 nm bandpass emission filter (L5 cube, Leica Microsystems). Photobleaching was minimized by using minimal light intensity to illuminate the slice in all experiments. Custom Labview (National Instruments) routines were used to simultaneously acquire electrophysiology and fluorescence data.

Two-photon laser scanning fluorescence microscopy. Two-photon laser scanning fluorescence microscopy (2PLSM) was performed using a modified Bio-Rad Radiance MPD system or with a microscope designed and built by J.W. and based on an Olympus BX51 frame. The specimen was illuminated with $830 \mathrm{~nm}$ light from a Ti:sapphire laser (Chameleon Ultra, Coherent Scientific; $80 \mathrm{MHz}$ repetition rate, 100-150 fs pulse width). Excitation light was focused onto the specimen using a $40 \times, 0.8$ NA water-immersion objective (Olympus). Emitted light was collected in the epifluorescence configuration through a $680 \mathrm{~nm}$ dichroic reflector and an infrared-blocking emission filter (ET700sp-2p, Chroma Technology). Fluorescence was split into red and green channels with a secondary dichroic reflector (570 DCXR, Chroma Technology) and detected via 490-560 $\mathrm{nm}$ and 575-645 nm bandpass filters (Chroma Technology) using photomultiplier tubes (R6357, Hamamatsu). Scanning and image acquisition were controlled using custom software written in Labview (National Instruments). Results were collected with line scans at 166 or $500 \mathrm{~Hz}$ perpendicular to the apical dendrite.

Calculation of intracellular calcium concentration from OGB-1 fluorescence. OGB-1 (Invitrogen) was added to the intracellular recording solution. For CCD experiments, steady-state calcium measurements were made after the amplitude and decay time constant of the calcium transient became stable through time ( $\geq 25 \mathrm{~min}$ after break-in). For 2PLSM experiments in which calcium transients were monitored during loading of indicator, changes in both the basal fluorescence and the peak ampli- tude of calcium transients evoked with single action potentials were measured repeatedly as indicator diffused into and reached steady-state within the apical dendrite, beginning 3-10 min after break-in and extending for up to 65 (typically 40-60) $\mathrm{min}$. The baseline fluorescence at each time point was calculated from the mean fluorescence in the first $250 \mathrm{~ms}$ of the trial, before any action potentials. The peak of the calcium transient was measured by fitting an exponential to the decaying phase of the transient and back extrapolating this fit to the time of the action potential.

Calculations were performed as described previously (Neher and Augustine, 1992; Neher, 1995; Maravall et al., 2000).

Calcium concentration was calculated using Equation 1 (Maravall et al., 2000):

$$
\frac{\Delta\left[\mathrm{Ca}^{2+}\right]}{K_{\mathrm{d}}}=\frac{F_{\max }}{F_{0}}\left(1-R_{\mathrm{f}}^{-1}\right) \frac{\Delta F / F}{\left((\Delta F / F)_{\max }-\Delta F / F\right) \cdot(\Delta F / F)_{\max }},
$$

where, $\Delta\left[\mathrm{Ca}^{2+}\right]$ is the rise in calcium concentration, $F_{\max }$ is the fluorescence at saturation, $F_{0}$ is the resting fluorescence, $R_{f}$ is the dynamic range of the indicator, $\Delta F / F$ is the change in fluorescence divided by the resting fluorescence, $(\Delta F / F)_{\max }$ is the $\Delta F / F$ at saturation.

We used a value of 8.5 for $R_{f}$ (for OGB-1) (Maravall et al., 2000). $F_{\max }$ was calculated for each recording from Equation 2, after using trains of action potentials at 50 and $100 \mathrm{~Hz}$ to establish maximal (plateau) $\Delta F / F$ values:

$$
(\Delta F / F)_{\max }=(\Delta F / F)_{\text {plateau }} \times 100 / x,
$$

where $x$ is a correction factor:

$$
x=100 \times \frac{1-Q \times(v 1 / v 2)}{1-(v 1 / v 2)},
$$

where $v 1$ and $v 2$ are the lower and higher frequencies driving the action potentials and $Q$ is the ration of plateau fluorescence at higher and lower frequencies (Maravall et al., 2000).

The resting calcium concentration $\left(\left[\mathrm{Ca}^{2+}\right]_{0}\right)$ was determined using equation 4 (Maravall et al., 2000):

$$
\frac{\left[\mathrm{Ca}^{2+}\right]_{0}}{K_{\mathrm{d}}}=\frac{1-R_{f}^{-1}}{(\Delta F / F)_{\max }}-R_{f}^{-1} .
$$

The buffer capacity of the indicator $\left(\kappa_{\mathrm{B}}\right)$ was calculated using equation 5 (Maravall et al., 2000):

$$
\kappa_{\mathrm{B}}=\frac{K_{\mathrm{d}} \times[\mathrm{B}]_{\mathrm{T}}}{\left(K_{\mathrm{d}}+\left[\mathrm{Ca}^{2+}\right]_{0}\right) \times\left(K_{\mathrm{d}}+\left[\mathrm{Ca}^{2+}\right]_{\text {peak }}\right)},
$$

where $[B]_{\mathrm{T}}$ is the total concentration of the dye used during the experiment, and $\left[\mathrm{Ca}^{2+}\right]_{\text {peak }}$ is the calcium concentration at the peak of the calcium transient.

Endogenous buffer capacities were calculated by back-extrapolation of the relationship between the reciprocal of the peak amplitude of the calcium transient and the exogenous buffer capacity (see Fig. 2C). Like previous authors, we found that the peak amplitude of the calcium transient declined during prolonged recording, leading to an abrupt upswing in the plot (Neher and Augustine, 1992; Maravall et al., 2000). This upswing occurred in all of our recordings, $34 \pm 2.9 \min (\max 50 \min ; n=15$ recordings) after obtaining the whole-cell configuration. Where steady-state was not achieved before the upswing occurred, the recording was excluded from further analysis. In recordings where a steady-state was achieved $>5 \mathrm{~min}$ before the upswing, we discarded points after the upswing.

Calculation of intracellular calcium concentration from OGB- $6 F$ fluorescence. During a train of action potentials, OGB-1 can approach saturation. Hence for some experiments, we used the lower-affinity indicator OGB-6F $\left(K_{\mathrm{d}}=3 \mu \mathrm{M}\right)$. We found that $150 \mu \mathrm{M}$ OGB-6F offers an adequate signal-to-noise ratio to resolve AP-evoked signals and enough dynamic range to avoid indicator saturation, but adds minimal buffer capacity to the neuron and therefore reports nearly unperturbed calcium signals. 
Table 1. Membrane properties of CA1 pyramidal neurons

\begin{tabular}{lcr}
\hline & \multicolumn{1}{c}{ Young } & \multicolumn{1}{c}{ Aging } \\
& 27 neurons & \multicolumn{1}{c}{ 22 neurons } \\
\hline Resting membrane potential $(\mathrm{mV})$ & $-66.6 \pm 0.7$ & $-66.3 \pm 1.1$ \\
Input resistance $(\mathrm{M} \Omega)$ & $67.6 \pm 3.0$ & $56.2 \pm 3.0$ \\
AP threshold $(\mathrm{mV})$ & $-49.6 \pm 1.3$ & $-52.1 \pm 1.1$ \\
AP amplitude $(\mathrm{mV})$ & $83.1 \pm 2.2$ & $86.7 \pm 1.8$ \\
AP half width (ms) & $0.85 \pm 0.03$ & $0.78 \pm 0.03$ \\
\hline
\end{tabular}

A summary of membrane properties of CA1 pyramidal neurons in young and aging rats. All values are mean \pm SEM
A
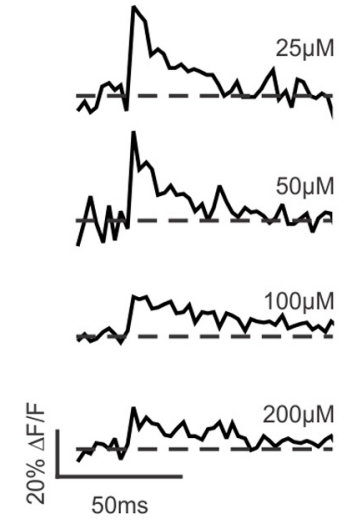

B
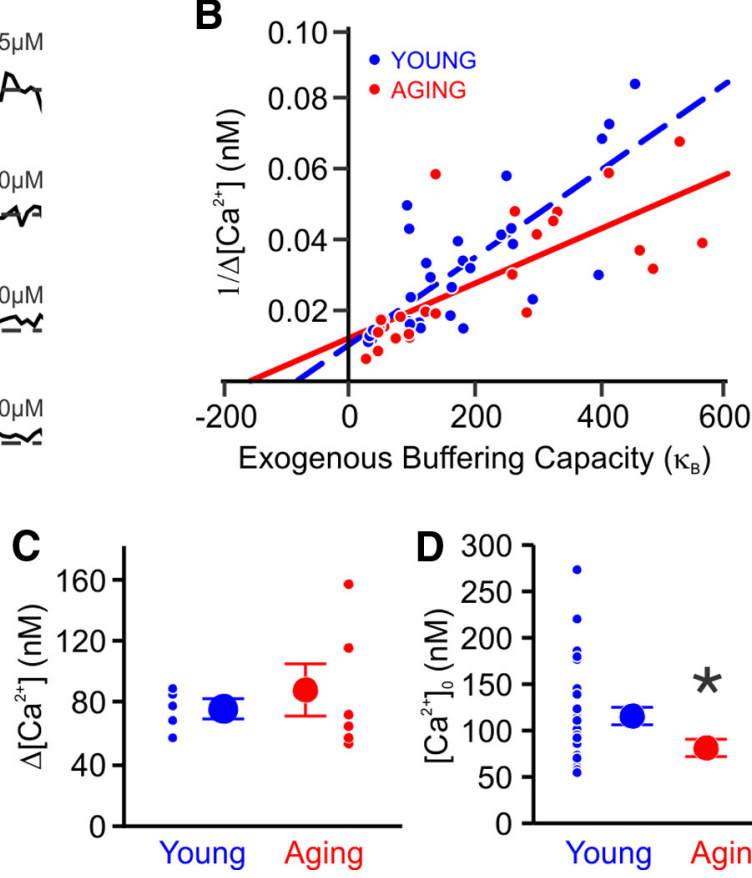

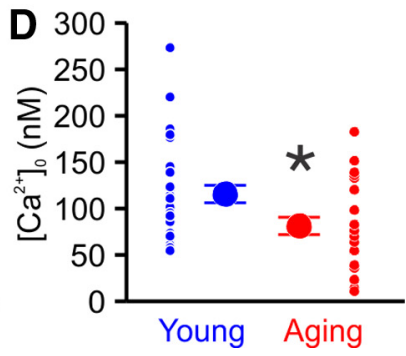

Figure 1. Endogenous buffer capacity is enhanced in aging CA1 pyramidal neurons. Widefield image of a CA1 pyramidal neuron loaded with $200 \mu \mathrm{m}$ 0GB-1 (bottom left). White box, Region of interest (ROI) where calcium transients were measured, $\sim 40 \mu \mathrm{m}$ from the soma. Dotted white boxes, Background regions. Scale bar, $40 \mu \mathrm{m}$. $A$, Example calcium transients evoked by an action potential in neurons loaded with different concentrations of $0 G B-1$ and measured using a CCD camera. $B$, Reciprocal amplitude of calcium transients $\left(1 / \Delta\left[C^{2+}\right]\right)$ plot against exogenous buffer capacity $\left(\kappa_{\mathrm{B}}\right.$ ). The $R$ values and the slopes of the linear extrapolation were 0.771 and $0.000,124$ ( $p$ values $<$ 0.0001 ) for young, and 0.742 and $0.000,078$ ( $p$ values $<0.0001$ ) for aging. Each point represents one neuron loaded with 25, 50,75, 100, 150, or $200 \mu \mathrm{m}$ 0GB-1 (29 neurons from 12 young adult rats, 24 neurons from 9 aged rats). C, No significant difference was observed in the peak amplitude of calcium transients evoked with single action potentials in CA1 neurons from young and aging rats that were loaded with $25 \mu \mathrm{M}$ 0GB-1 ( 5 neurons from 3 young adult rats, 6 neurons from 5 aged rats). The figure illustrates the data obtained for each individual neuron (small circles) and the mean \pm SEM (larger circle). D, Resting calcium concentration in young and aging CA1 neurons (29 neurons from 12 young adult rats, 24 neurons from 9 aged rats).

The approach of Maravall et al. (2000) is less suited to the calibration of calcium signals with OGB-6F and we therefore used the approach described by Bloodgood and Sabatini (2007). We simultaneously measured the fluorescence of OGB-6F and Alexa 594. Calcium transients were quantified as increases in green (OGB-6F) fluorescence divided by the red (Alexa 594) fluorescence. Calcium concentrations were then calculated using Equation 6 (Bloodgood and Sabatini, 2007):

$$
\frac{G / R}{G_{\max } / R}=\frac{\left[\mathrm{Ca}^{2+}\right]}{\mathrm{K}_{\mathrm{d}}},
$$

where, $G_{\max } / R$ is the $G / R$ ratio at saturation.

We measured $G_{\max } / R$ by imaging a pipette containing intracellular solution (including OGB-6F and Alexa 594) and $1 \mathrm{M} \mathrm{CaCl}_{2}$ (Bloodgood and Sabatini, 2007).

Statistical analysis. Results were analyzed using custom routines written in IgorPro v6.2.1 (WaveMetrics). Statistical analyses were performed with Statview v5.0.1, (Sigma-Aldrich) Plot v11 and Systat v12 software. Unless indicated otherwise, results are shown as mean \pm SEM.

\section{Results}

Calcium buffer capacity is increased in aging CA1 neurons CA1 pyramidal neurons in young and aging male Fischer 34 Brown Norway rats. Basic membrane properties and spike waveforms were similar in young and aging rats (Table 1 ). To investigate calcium handling in these neurons we used the "added buffer" approach, in which many parameters underlying calcium handling are measured from the change in amplitude and time course of intracellular calcium signals when additional calcium buffer, in the form of calcium indicator, is added to the neuron (Neher and Augustine, 1992; Helmchen et al., 1996). Different concentrations of OGB-1 were added to the cytoplasm of CA1 neurons through the recording pipette, resulting in neurons containing different exogenous calcium buffer capacities $\left(\kappa_{\mathrm{B}}\right)$. Steady-state level of OGB-1 was determined for each neuron before data collection by ensuring that the single action potential evoked calcium measurements (the amplitude and decay time constant) were stable after $\geq 25 \mathrm{~min}$ of OGB-1 loading. As expected, in neurons from both young and aged rats, an action potential evoked large, rapidly decaying relative changes in fluorescence $(\Delta F / F)$ in neurons loaded with low concentrations of OGB-1 and smalleramplitude, slower-decaying fluorescence transients in neurons containing higher concentrations of the indicator (Fig. 1A).

We estimated the unperturbed change in intracellular calcium concentration that would have been observed in the absence of OGB-1 $\left(\kappa_{\mathrm{B}}=0\right)$ (Fig. $\left.1 B\right)$ and the endogenous calcium buffer capacity $\left(\kappa_{s}\right.$ : $x$-intercept -1 ) (Fig. $1 B$ ) by plotting the peak amplitudes of calcium transients $\left(\Delta\left[\mathrm{Ca}^{2+}\right]\right)$ in response to a single action potential as a function of the buffer capacity of the indicator $\left(\kappa_{\mathrm{B}}\right)$. The peak amplitude of the unperturbed calcium transient was similar for CA1 neurons from the two age groups (Fig. $1 B$ ) (young $83 \mathrm{~nm}$; aging $100 \mathrm{~nm}$ ) and was also similar in neurons loaded with a low concentration of indicator ( $25 \mu \mathrm{M}$ OGB-1, young $76 \pm 6 \mathrm{nM}$; aging $88 \pm 17 \mathrm{~nm}, p>0.05$ ) (Fig. $1 C$ ). The endogenous buffer capacity in young rats was 80 , similar to that previously reported for neonatal CA1 neurons (Helmchen et al., 1996; Maravall et al., 2000), but for aging CA1 neurons was 155 . We also measured the resting intracellular calcium concentration, which was reduced by $\sim 30 \%$ in CA1 neurons from aging rats, from $115 \pm 10 \mathrm{~nm}$ in young adults to $81 \pm 9 \mathrm{nM}$ in aging rats $(p<0.05)$ (Fig. $1 D)$. Hence, aging neurons contain almost twice as much endogenous calcium buffer as neurons from young adult rats.

These results are the first to demonstrate enhanced endogenous calcium buffer capacity and reduced resting calcium concentration in apical dendrites of CA1 neurons from aging animals. However, these measurements were necessarily made at steadystate, 25-30 min after break-in and after dialysis of the neuronal 
cytoplasm with pipette solution. Hence, mobile endogenous buffers may have been lost before our measurements were made. In addition, it is difficult to place confidence intervals on the endogenous buffer capacities calculated in this manner (but see Aponte et al., 2008). We therefore performed additional measurements using a similar approach, but measuring calcium transients during diffusion of indicator into the neuron. This permits calculation of the endogenous buffer capacity and unperturbed calcium transient for each individual neuron (Helmchen et al., 1996; Maravall et al., 2000) and therefore facilitates statistical comparison of measurements from young and aging neurons.

Changes in the basal fluorescence $\left(f_{0}\right)$ and calcium transients evoked with single action potentials were measured repeatedly as $100 \mu \mathrm{M}$ OGB-1 diffused into and reached a steady-state concentration within the apical dendrite (Fig. 2). These dynamic measurements yielded almost identical results to those made under steady-state conditions. There was no difference in the unperturbed peak calcium concentration evoked with a single action potential (Fig. $2 E$ ), but endogenous buffer capacities differed in young and aging neurons (Fig. 2D) (39 \pm 6 in young and $70 \pm 10$ in aging neurons, $p<0.05$, unpaired $t$ test). Hence endogenous buffer capacity is elevated in aging neurons.

We would expect an elevated endogenous calcium buffer capacity to slow the time course of calcium changes in aging rats (Helmchen and Tank, 2005). We compared the rate of change in calcium concentration in young and aging rats during trains of action potentials at $50 \mathrm{~Hz}$. As expected, the rate of rise of the fluorescence was slower in neurons from aging than from young adult rats (Fig. $3 A$ ) (young $60 \pm 5 \mathrm{~ms}$, aging $80 \pm 8 \mathrm{~ms}, p<0.05)$.

\section{Calcium influx is increased in aging CA1 neurons}

In the absence of other changes in calcium handling, elevated calcium buffering is expected to reduce the peak amplitude of the dendritic calcium transient in aging rats (Helmchen and Tank, 2005). Why then, is the mean peak amplitude of the action potential-evoked calcium transient not smaller in aging than in young adult rats? One possibility is that calcium influx is enhanced in aging rats. Previous studies have reported that during a train of action potentials there is a greater rise in cytosolic calcium concentration in CA1 neurons from aging animals, due to enhanced calcium influx via L-type channels (Moyer and Disterhoft, 1994; Thibault and Landfield, 1996) and possibly increased calciuminduced calcium release (Kumar and Foster, 2005; Gant et al., 2006). We therefore compared calcium influx into CA1 neurons in young and aging rats. We added a large amount of indicator to overwhelm endogenous buffers, thereby ensuring that the indicator captured almost all the incoming calcium. Under these conditions the change
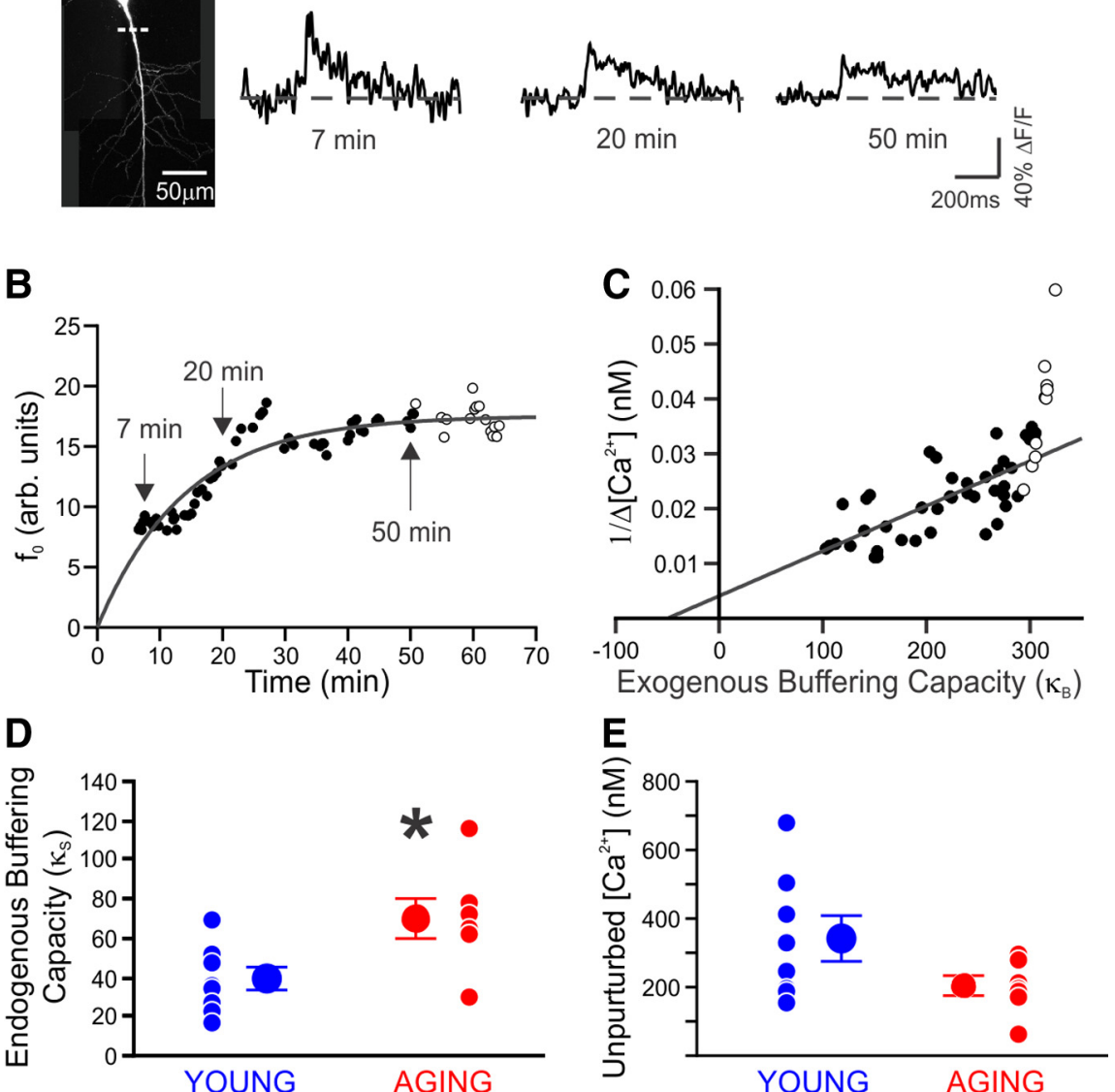

Figure 2. Endogenous buffer capacity and unperturbed calcium transient measured in individual neurons. $\boldsymbol{A}$, Maximum inten( $f_{0}$, arbitrary units) over time as 0GB-1 diffused into and approached a steady-state concentration in the dendrite. oints are fit with an exponential. C, Example of endogenous buffer capacity calculated by back-extrapolation of the relationship between the reciprocal amplitude of calcium transients $\left(1 / \Delta\left[\mathrm{Ca}^{2+}\right]\right)$ plot against exogenous buffer capacity $\left(\kappa_{B}\right)$ for the results in (open circles) were discarded before fitting a line through the results. $\boldsymbol{D}$, The endogenous buffer ity is significantly enhanced in neurons from aging rats ( ${ }^{*} p<0.05$, unpaired $t$ test). $\boldsymbol{E}$, Peak amplitude of the unperturbed calcium transient evoked with a single action potential is not significantly altered with aging (young, 8 neurons from 4 rats, $342 \pm$ $65 \mathrm{~nm}$; aging, 7 neurons from 5 rats, $206 \pm 29 \mathrm{~nm}$ ).

in fluorescence $(\Delta F)$ is proportional to the calcium flux across the membrane (Neher, 1995). CA1 neurons were loaded with $500 \mu \mathrm{M}$ OGB-1, which has at least tenfold greater buffer capacity than the endogenous buffers. Calcium influx evoked with trains of 20-100 action potentials at $20-100 \mathrm{~Hz}$ was $\geq 50 \%$ greater in CA1 neurons from aging than from young rats (Fig. $3 C, D)(p<0.05$, unpaired $t$ test).

Hence our results indicate that endogenous buffer capacity and calcium influx are both increased in aging CA1 pyramidal neurons. These two changes will have opposing effects on the amplitudes of calcium transients and our results indicate that these two changes balance each other, such that the amplitudes of calcium transients evoked by single action potentials are similar in young and aging neurons.

Increased calcium buffer capacity is overwhelmed with repeated activity in aging CA1 neurons

In behaving animals CA1 pyramidal neurons often spike in repetitive bursts at theta frequencies (O'Keefe, 2007). During bursts, intracellular calcium may accumulate and overwhelm en- 

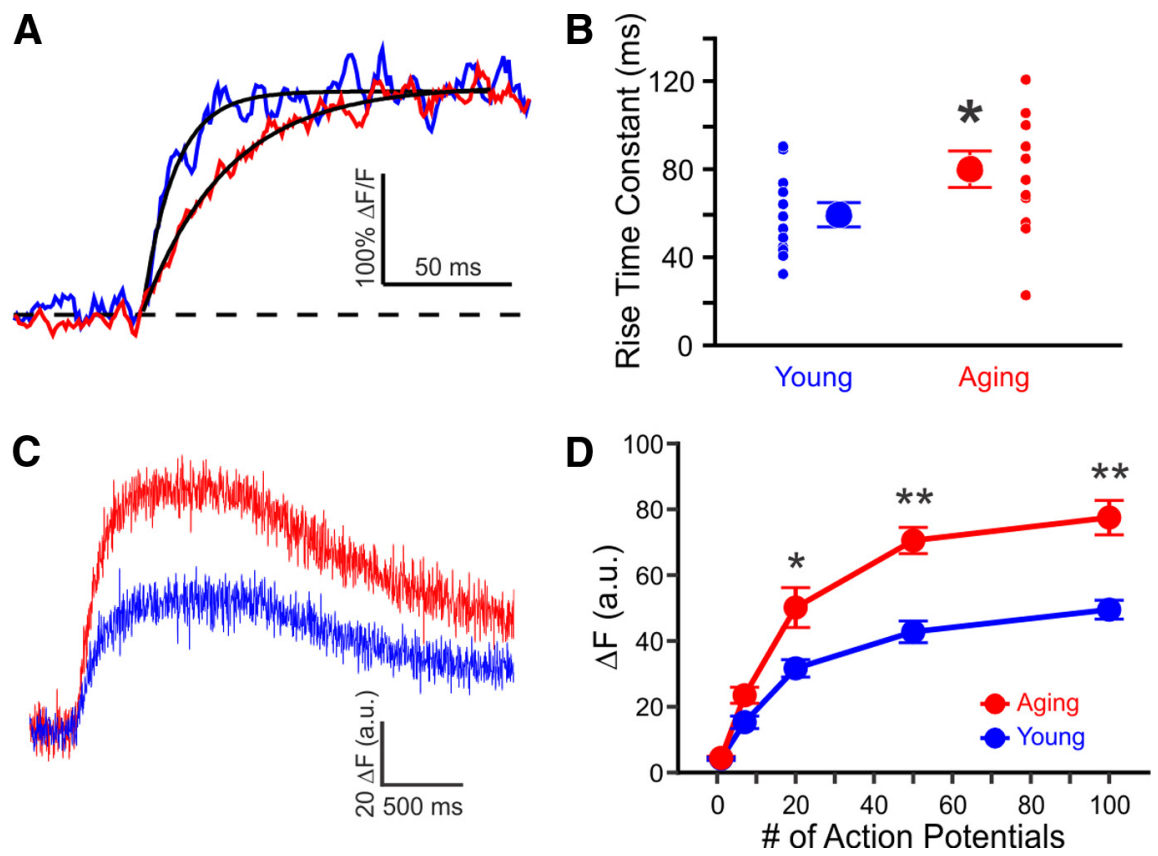

Figure 3. Rise time and amplitude of calcium influx are increased in aging CA1 neurons. $A$, Example measurements evoked with $50 \mathrm{~Hz}$ train of action potentials from young (blue) and aging (red) neurons loaded with $100 \mu \mathrm{m}$ OGB-1. For illustrative purposes, only the initial rise to plateau phase is shown. $B$, Rise time constants in CA1 neurons from young ( $60 \pm 5 \mathrm{~ms}, n=12$ from 9 rats) and aging ( $80 \pm 8 \mathrm{~ms}, n=12$ from 10 rats) rats measured with $100 \mu \mathrm{m}$ OGB-1 during a train of action potentials at $50 \mathrm{~Hz}$. C, Example measurements from young (blue) and aging (red) neurons loaded with 500 $\mu \mathrm{M} 0 \mathrm{~GB}-1$, during 100 action potentials at $100 \mathrm{~Hz}$. D, Steady-state rise in fluorescence $(\Delta F)$ during $1 \mathrm{~s}$ trains of action potentials, measured with $500 \mu \mathrm{m}$ OGB-1. Young, $n=4$ from 3 rats. Aging, $n=5$ from 4 rats. ${ }^{*} p<0.05$, ${ }^{* *} p<0.005$, unpaired $t$ test.

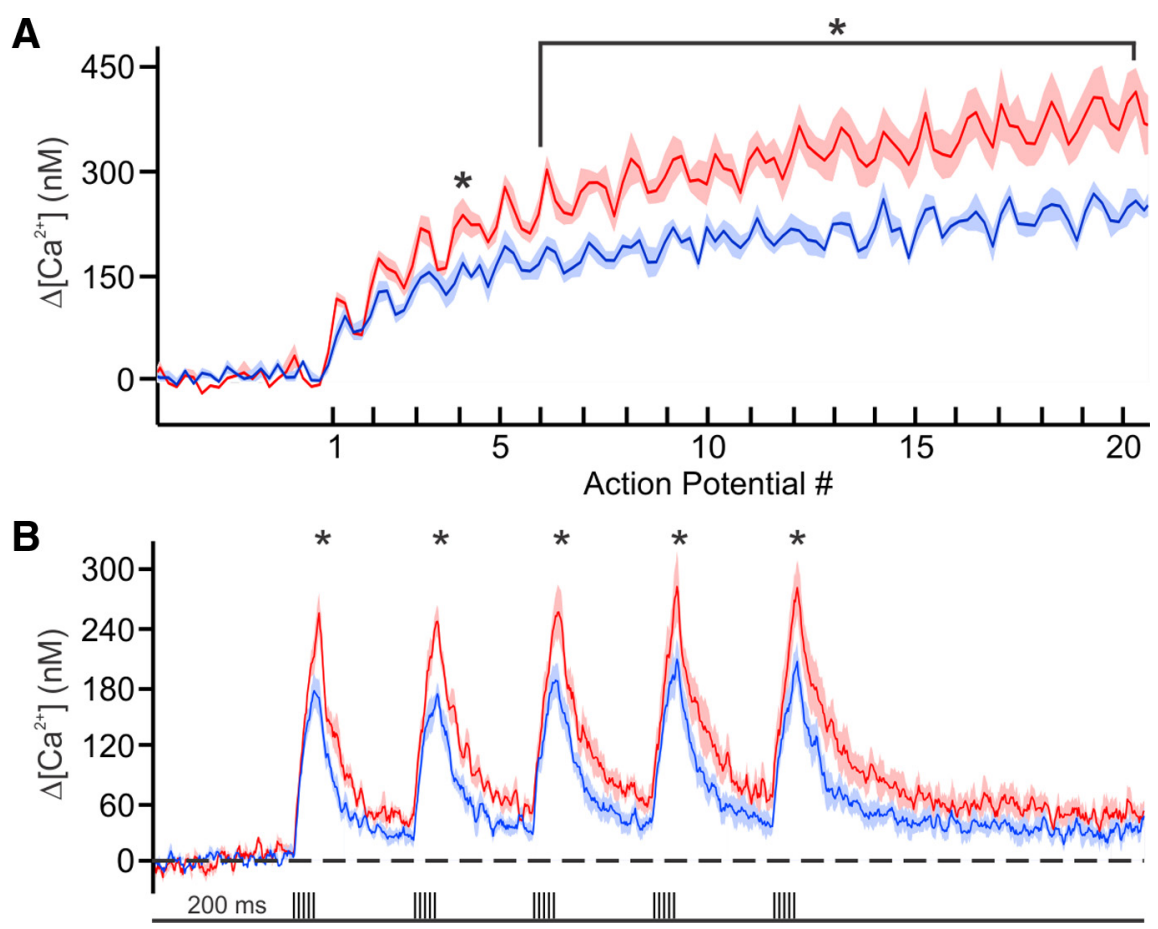

Figure 4. Calcium concentration during trains of action potentials. $\boldsymbol{A}$, Mean calcium concentrations (shaded regions represent SEM) during $100 \mathrm{~Hz}$ trains in young (blue, $n=6$ from 2 rats) and aging (red, $n=6$ from 3 rats) neurons loaded with $150 \mu \mathrm{m}$ 0GB-6F. B, Calcium concentration during theta burst activity ( 5 action potentials at $100 \mathrm{~Hz}$ ) at theta frequency ( $5 \mathrm{~Hz}$ ). Significant differences were revealed with repeated ANOVAs for the $100 \mathrm{~Hz}$ and theta burst activity. Further analysis revealed significant differences between the age groups at various points during the train of activity. ${ }^{*} p<0.05$. dogenous calcium buffers, resulting in a higher free cytosolic calcium concentration in aging than in young CA1 pyramidal neurons. Thus, we monitored calcium concentration during sustained spiking at $100 \mathrm{~Hz}$ and during theta-like activity. For these experiments we filled neurons with $150 \mu \mathrm{M}$ Oregon green BAPTA-6 (OGB$6 \mathrm{~F})$, which has a low enough affinity that it has little effect on calcium buffer capacity. During $100 \mathrm{~Hz}$ trains, the calcium concentrations in young and aging neurons were similar during the first three action potentials, but thereafter became larger in aging than in young neurons (Fig. $4 A$ ). Similarly, during theta burst activity peak calcium concentrations were greater in CA1 neurons from aging rats (Fig. 4B). Hence, if increased calcium buffering is a cellular mechanism to combat increased calcium influx in aging CA1 neurons, this protection is only effective during the first few action potentials of a train: thereafter the intracellular calcium concentration is higher in the proximal apical dendrites of CA1 pyramidal neurons in aging than in young adult rats.

\section{Discussion}

Our results are the first to demonstrate enhanced endogenous calcium buffer capacity in the apical dendrites of CA1 hippocampal pyramidal neurons from aging animals. Buffer capacity in intact CA1 pyramidal neurons had not been directly measured, but was previously thought to decrease with age (Toescu and Verkhratsky, 2007; Kumar et al., 2009)

In this study, we did not identify the calcium buffer that is elevated with aging. More than 200 proteins that bind, and therefore buffer calcium, have been identified (Miller, 1991; Braunewell and Gundelfinger, 1999; Heizmann, 1999; Lewit-Bentley and Rety, 2000; Burgoyne et al., 2004; Schwaller, 2009). Some, such as parvalbumin, calbindin- $\mathrm{D}_{28}$, calretinin, hippocalcin, and visinin-like $\mathrm{Ca}^{2+}$ binding protein 2 (NVP2) are often reduced with normal aging (Villa et al., 1994; de Jong et al., 1996; Krzywkowski et al., 1996; Kishimoto et al., 1998; Furuta et al., 1999), suggesting that the increase in calcium buffering is more likely to result from changes in expression of other proteins, perhaps of a "nonclassical" calcium buffer protein that requires $\mathrm{Ca}^{2+}$ for its activity (e.g., adenyl cyclase I or III (ACI/ III) and calcineurin) (Berridge et al., 2000; Schwaller, 2009). Calcineurin is one such nonclassical buffer protein that displays increased activity (Foster et al., 2001; Eto et al., 2008). 
Contrary to previous reports (Hajieva et al., 2009), we found that the resting $\left[\mathrm{Ca}^{2+}\right]$ is reduced in aging CA1 neurons. Enhanced buffer capacity in aging neurons is unlikely to account for the reduction in resting calcium: endogenous calcium buffer capacity impacts the dynamics of calcium signals, but has little effect on steady-state parameters, such as the resting calcium concentration (Neher and Augustine, 1992; Neher, 1995). Furthermore, the resting $\left[\mathrm{Ca}^{2+}\right]$ was not correlated with buffer capacity (data not shown). Hence, our results suggest that alteration in other cellular mechanisms, such as intracellular stores or plasma membrane calcium pumps, is responsible for the significantly reduced resting $\left[\mathrm{Ca}^{2+}\right]$ in CA1 neurons with normal aging.

Our experiments did not directly test the roles of intracellular stores in shaping action potential-evoked calcium transients. In the apical dendrites of cortical pyramidal neurons from young rats, uptake of calcium into the endoplasmic reticulum does not play a significant role in determining the amplitudes of single action potential-evoked calcium transients (Markram et al., 1995), but helps to clear calcium from the cytoplasm during the decay of action potential-evoked calcium signals (Markram et al., 1995). Hence, intracellular stores are likely to influence calcium accumulation during repeated spiking, probably in both young and aging animals. Because calcium accumulation by and release from intracellular organelles may change with aging (Kumar and Foster, 2005; Mattson, 2007), aging-related changes in intracellular stores may have contributed to the age dependence of calcium accumulation that we observed during $100 \mathrm{~Hz}$ and theta burst spiking. Presumably if there are aging-related changes to intracellular stores or to calcium extrusion pathways, these changes would combine with the changes in calcium handling mechanisms that we have documented to determine the rate of saturation of calcium buffers in aging animals. For example, increased calcium release via ryanodine receptors (Gant et al., 2006) and enhanced buffering might counteract each other, with the balance of these two factors determining how quickly buffers saturate during action potential firing.

The postburst after hyperpolarization (AHP) is a $\mathrm{Ca}^{2+}$ dependent potassium current and has been suggested to be a biomarker of intrinsic neuronal excitability because it appears to be an important regulator of learning in the hippocampus (Disterhoft and Oh, 2006). The postburst AHP is significantly enlarged in CA1 neurons from aging, relative to young animals and this increase is linked to age-related learning impairments (Disterhoft and Oh, 2006). The enhancement in the postburst AHP with aging neatly parallels the changes in calcium accumulation reported here: the postburst AHP evoked with a few action potentials is of similar amplitude in young and aging neurons (Landfield and Pitler, 1984), whereas the postburst AHP following sustained spiking is larger in aging than in young neurons (Landfield and Pitler, 1984; Disterhoft and Oh, 2007; Matthews et al., 2009). Similar increases in calcium accumulation evoked with a sustained $7 \mathrm{~Hz}$ (Thibault et al., 2001; Gant et al., 2006) or brief $100 \mathrm{~Hz}$ (Hemond and Jaffe, 2005) train of action potentials have been previously reported in CA1 pyramidal neurons from aged rats. It appears likely, therefore, that the enhanced accumulation of calcium in aging neurons is the primary cause of the enlarged AHP during prolonged spiking. Enhanced L-type voltage-gated calcium current and calcium-induced calcium release following a burst of action potentials have previously been identified as causes of the aging-related increase in postburst AHP (Landfield and Pitler, 1984; Moyer and Disterhoft, 1994; Power et al., 2002; Kumar and Foster, 2004, 2005; Gant et al., 2006), and our results indicate that increasing calcium buffering blunts the enhanced calcium accumulation in aging rats, but fails to prevent the agingrelated increase in calcium influx following a burst of action potentials. Hence, the increase in calcium buffering that we have documented probably improves, but undoubtedly fails, to entirely recover hippocampus-dependent cognitive function in aging.

\section{References}

Aponte Y, Bischofberger J, Jonas P (2008) Efficient $\mathrm{Ca}^{2+}$ buffering in fastspiking basket cells of rat hippocampus. J Physiol 586:2061-2075. CrossRef Medline

Berridge MJ, Lipp P, Bootman MD (2000) The versatility and universality of calcium signalling. Nat Rev Mol Cell Biol 1:11-21. CrossRef Medline

Bloodgood BL, Sabatini BL (2007) Nonlinear regulation of unitary synaptic signals by $\mathrm{CaV}(2.3)$ voltage-sensitive calcium channels located in dendritic spines. Neuron 53:249-260. CrossRef Medline

Braunewell KH, Gundelfinger ED (1999) Intracellular neuronal calcium sensor proteins: a family of EF-hand calcium-binding proteins in search of a function. Cell Tissue Res 295:1-12. CrossRef Medline

Burgoyne RD, O'Callaghan DW, Hasdemir B, Haynes LP, Tepikin AV (2004) Neuronal $\mathrm{Ca}^{2+}$-sensor proteins: multitalented regulators of neuronal function. Trends Neurosci 27:203-209. CrossRef Medline

de Jong GI, Naber PA, Van der Zee EA, Thompson LT, Disterhoft JF, Luiten PG (1996) Age-related loss of calcium binding proteins in rabbit hippocampus. Neurobiol Aging 17:459-465. CrossRef Medline

Disterhoft JF, Oh MM (2006) Learning, aging and intrinsic neuronal plasticity. Trends Neurosci 29:587-599. CrossRef Medline

Disterhoft JF, Oh MM (2007) Alterations in intrinsic neuronal excitability during normal aging. Aging Cell 6:327-336. CrossRef Medline

Disterhoft JF, Gispen WH, Traber J, Khachaturian AS (1994) Calcium hypothesis of aging and dementia. Ann NY Acad Sci 747.

Eto R, Abe M, Hayakawa N, Kato H, Araki T (2008) Age-related changes of calcineurin and Akt1/protein kinase Balpha (Akt1/PKBalpha) immunoreactivity in the mouse hippocampal CA1 sector: an immunohistochemical study. Metab Brain Dis 23:399-409. CrossRef Medline

Foster TC, Sharrow KM, Masse JR, Norris CM, Kumar A (2001) Calcineurin links $\mathrm{Ca}^{2+}$ dysregulation with brain aging. J Neurosci 21:4066-4073. Medline

Furuta Y, Kobayashi M, Masaki T, Takamatsu K (1999) Age-related changes in expression of hippocalcin and NVP2 in rat brain. Neurochem Res 24:651-658. CrossRef Medline

Gant JC, Sama MM, Landfield PW, Thibault O (2006) Early and simultaneous emergence of multiple hippocampal biomarkers of aging is mediated by $\mathrm{Ca}^{2+}$-induced $\mathrm{Ca}^{2+}$ release. J Neurosci 26:3482-3490. CrossRef Medline

Gibson GE, Peterson C (1987) Calcium and the aging nervous system. Neurobiol Aging 8:329-343. CrossRef Medline

Hajieva P, Kuhlmann C, Luhmann HJ, Behl C (2009) Impaired calcium homeostasis in aged hippocampal neurons. Neurosci Lett 451:119-123. CrossRef Medline

Heizmann CW (1999) $\mathrm{Ca}^{2+}$-binding S100 proteins in the central nervous system. Neurochem Res 24:1097-1100. CrossRef Medline

Helmchen F, Tank DW (2005) A single-compartment model of calcium dynamics in nerve terminals and dendrites. In: Imaging in neuroscience and development: a laboratory manual (Yuste R, Konnerth A, eds), pp 265-276. Cold Spring Harbor, NY: Cold Spring Harbor Laboratory.

Helmchen F, Imoto K, Sakmann B (1996) $\mathrm{Ca}^{2+}$ buffering and action potential-evoked $\mathrm{Ca}^{2+}$ signaling in dendrites of pyramidal neurons. Biophys J 70:1069-1081. CrossRef Medline

Hemond P, Jaffe DB (2005) Caloric restriction prevents aging-associated changes in spike-mediated $\mathrm{Ca}^{2+}$ accumulation and the slow afterhyperpolarization in hippocampal CA1 pyramidal neurons. Neuroscience 135: 413-420. CrossRef Medline

Khachaturian ZS (1989) Calcium, membranes, aging, and Alzheimer's disease: introduction and overview. Ann N Y Acad Sci 568:1-4. CrossRef Medline

Kirischuk S, Verkhratsky A (1996) Calcium homeostasis in aged neurones. Life Sci 59:451-459. CrossRef Medline

Kishimoto J, Tsuchiya T, Cox H, Emson PC, Nakayama Y (1998) Agerelated changes of calbindin-D28k, calretinin, and parvalbumin mRNAs in the hamster brain. Neurobiol Aging 19:77-82. CrossRef Medline 
Krzywkowski P, Potier B, Billard JM, Dutar P, Lamour Y (1996) Synaptic mechanisms and calcium binding proteins in the aged rat brain. Life Sci 59:421-428. CrossRef Medline

Kumar A, Foster TC (2004) Enhanced long-term potentiation during aging is masked by processes involving intracellular calcium stores. J Neurophysiol 91:2437-2444. CrossRef Medline

Kumar A, Foster TC (2005) Intracellular calcium stores contribute to increased susceptibility to LTD induction during aging. Brain Res 1031: 125-128. CrossRef Medline

Kumar A, Bodhinathan K, Foster TC (2009) Susceptibility to calcium dysregulation during brain aging. Front Aging Neurosci 1:2. CrossRef Medline

Landfield PW (1987) "Increased calcium-current" hypothesis of brain aging. Neurobiol Aging 8:346-347. CrossRef Medline

Landfield PW, Pitler TA (1984) Prolonged $\mathrm{Ca}^{2+}$-dependent afterhyperpolarizations in hippocampal neurons of aged rats. Science 226:1089-1092. CrossRef Medline

Lewit-Bentley A, Réty S (2000) EF-hand calcium-binding proteins. Curr Opin Struct Biol 10:637-643. CrossRef Medline

Maravall M, Mainen ZF, Sabatini BL, Svoboda K (2000) Estimating intracellular calcium concentrations and buffering without wavelength ratioing. Biophys J 78:2655-2667. CrossRef Medline

Markram H, Helm PJ, Sakmann B (1995) Dendritic calcium transients evoked by single back-propagating action potentials in rat neocortical pyramidal neurons. J Physiol 485:1-20. Medline

Matthews EA, Linardakis JM, Disterhoft JF (2009) The fast and slow afterhyperpolarizations are differentially modulated in hippocampal neurons by aging and learning. J Neurosci 29:4750-4755. CrossRef Medline

Mattson MP (2007) Calcium and neurodegeneration. Aging Cell 6:337350. CrossRef Medline

McKay BM, Matthews EA, Oliveira FA, Disterhoft JF (2009) Intrinsic neuronal excitability is reversibly altered by a single experience in fear conditioning. J Neurophysiol 102:2763-2770. CrossRef Medline

Michaelis ML, Foster CT, Jayawickreme C (1992) Regulation of calcium levels in brain tissue from adult and aged rats. Mech Ageing Dev 62:291306. CrossRef Medline

Miller RJ (1991) The control of neuronal $\mathrm{Ca}^{2+}$ homeostasis. Prog Neurobiol 37:255-285. CrossRef Medline

Moyer JR Jr, Disterhoft JF（1994） Nimodipine decreases calcium action po- tentials in rabbit hippocampal CA1 neurons in an age-dependent and concentration-dependent manner. Hippocampus 4:11-17. CrossRef Medline

Moyer JR Jr, Brown TH (1998) Methods for whole-cell recording from visually preselected neurons of perirhinal cortex in brain slices from young and aging rats. J Neurosci Methods 86:35-54. CrossRef Medline

Murchison D, Griffith WH (1998) Increased calcium buffering in basal forebrain neurons during aging. J Neurophysiol 80:350-364. Medline

Neher E (1995) The use of fura-2 for estimating Ca buffers and Ca fluxes. Neuropharmacology 34:1423-1442. CrossRef Medline

Neher E, Augustine GJ (1992) Calcium gradients and buffers in bovine chromaffin cells. J Physiol 450:273-301. Medline

O'Keefe J (2007) Hippocampal neurophysiology in the behaving animal. In: The hippocampus book (Andersen P, Morris RG, Amaral DG, Bliss TV, O’Keefe J, eds), pp 475-548. New York: Oxford UP.

Power JM, Wu WW, Sametsky E, Oh MM, Disterhoft JF (2002) Age-related enhancement of the slow outward calcium-activated potassium current in hippocampal CA1 pyramidal neurons in vitro. J Neurosci 22:7234-7243. Medline

Schwaller B (2009) The continuing disappearance of "pure" $\mathrm{Ca}^{2+}$ buffers. Cell Mol Life Sci 66:275-300. CrossRef Medline

Thibault O, Landfield PW (1996) Increase in single L-type calcium channels in hippocampal neurons during aging. Science 272:1017-1020. CrossRef Medline

Thibault O, Hadley R, Landfield PW (2001) Elevated postsynaptic $\left[\mathrm{Ca}^{2+}\right]_{i}$ and L-type calcium channel activity in aged hippocampal neurons: relationship to impaired synaptic plasticity. J Neurosci 21:9744-9756. Medline

Toescu EC, Verkhratsky A (2007) The importance of being subtle: small changes in calcium homeostasis control cognitive decline in normal aging. Aging Cell 6:267-273. CrossRef Medline

Tonkikh A, Janus C, El-Beheiry H, Pennefather PS, Samoilova M, McDonald P, Ouanounou A, Carlen PL (2006) Calcium chelation improves spatial learning and synaptic plasticity in aged rats. Exp Neurol 197:291-300. CrossRef Medline

Villa A, Podini P, Panzeri MC, Racchetti G, Meldolesi J (1994) Cytosolic $\mathrm{Ca}^{2+}$ binding proteins during rat brain ageing: loss of calbindin and calretinin in the hippocampus, with no change in the cerebellum. Eur J Neurosci 6:1491-1499. CrossRef Medline 